\title{
رهانات إصلاح هياكل الإدارة الجبائية في الجزائر
}

\author{
Bases of reform of fiscal management structures in Algeria \\ تاريخ الاستلام : 2019/04/15 ؛ تاريخ القبول : 2019/05/30
}

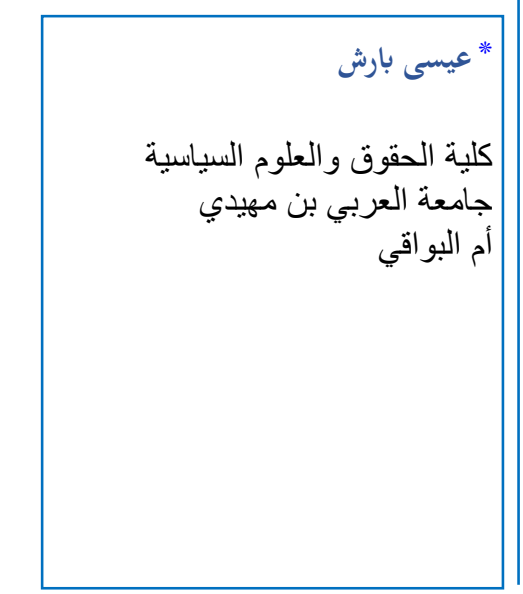

\section{Abstract}

he Commission has a great role in the economic development of each country thanks to the financial resources of the public treasury, as well as the collection of funds as an instrument for the implementation of economic policies and the economics of countries in a permanent development that requires the Algerian legislator to keep pace with the economic changes of the state by enacting legislation compatible with the stage and achieve development. It should be supported by a structural reform of the tax administration for the effective implementation of the legislation. However, Algeria has not achieved the desired goals and the tax policies have remained in place. Despite the considerable funds spent on these reforms and To improvise in her portrayal on the ground and effectively so great tax administration can keep up with the times and achieve the desired goals and see this for several reasons which we will discuss in this research paper.

Keywords: Tax - Administration Tax Development - Tax Reform - Information technologies

\section{Résumé}

La Commission joue un rôle important dans le développement économique de chaque pays grâce aux ressources financières du trésor public ainsi qu'à la collecte de fonds en tant qu'instrument de mise en œuvre des politiques économiques et de l'économie des pays dans un développement permanent qui oblige le législateur algérien à suivre le rythme des mutations économiques de l'État en promulguant une législation compatible avec le stade et réaliser le développement. Il devrait être soutenu par une réforme structurelle de l'administration fiscale pour une mise en œuvre effective de la législation. Cependant, l'Algérie n'a pas atteint les objectifs souhaités et les politiques fiscales sont restées en place. Improviser dans sa représentation sur le terrain et efficacement si grande administration fiscale peut maintenir avec le temps et atteindre les objectifs souhaités et voir ce pour plusieurs raisons dont nous parlerons dans ce document de recherche.

Mots clés Fiscalité - Administration Fiscalité Développement - Réforme fiscale Technologies de l'information

* Corresponding author, e-mail: aissa_bareche@ @otmail.fr 


\section{المقدمة :}

باشرت الحكومات الجزائرية المتعاقبة إصلاحات عديدة فيما يخص التشريعات

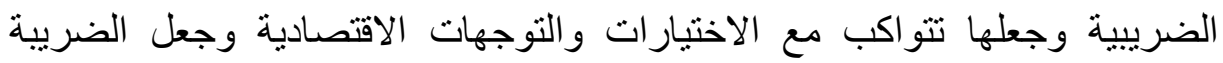

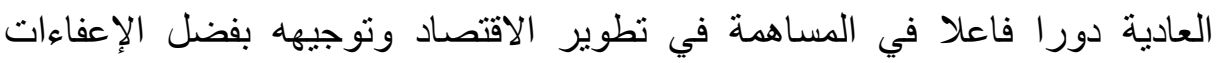

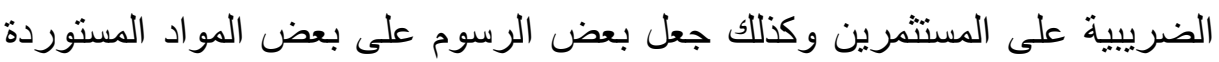

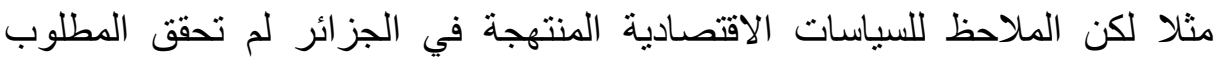

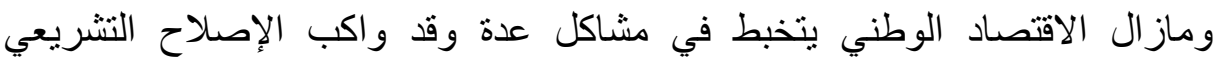
الضريبي إصلاح هياكل الإدارة الضريبية في الجزائر ولذا يمكن طرح التساؤل ولائل التالي

ماهي الأسباب التي جعلت النظام الجبائي الجزائري لا يو اكب التطورات الاقتصادية ؟

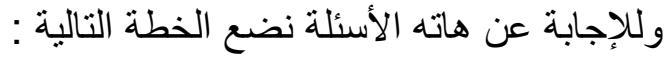

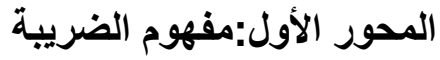

أولا : تعريف الضريبة الاون:مفوم الضرية

ثانيا :مقومات الضريبة : تونية

ثالثا :تقييم السياسة الضريات الضريبة البية في الجزائر

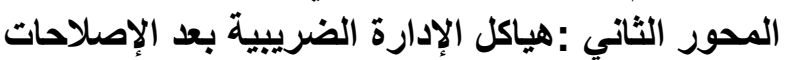
أولا :مديرية كبريات المؤسئات الأبسات ثانيا:مركز الضرائب

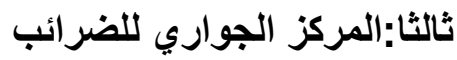
الخاتمة . الماتمر

المحور الأول:مفهوم الضريبة:

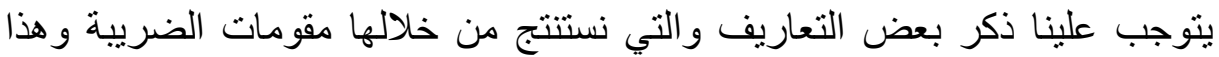

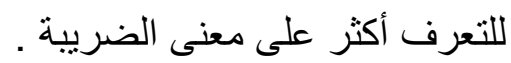
أولا :تعريف الضريبة ألية

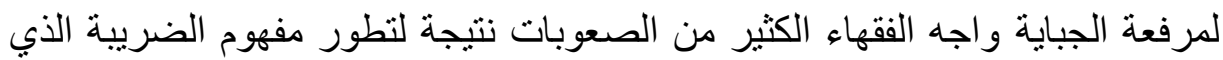
اختلف من وقت لآخر في سبيل تعريف الضريبة، فالتعريفات التي أطلقت عليه التهاء اختلفت فيما بينها نظرا لتغير طبيعة ومبررات الضريبة فئرية مع تغير النظم السياسية

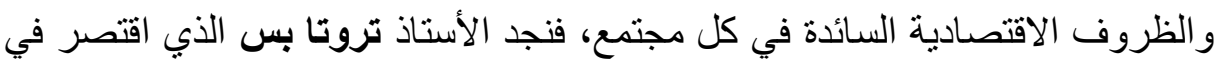

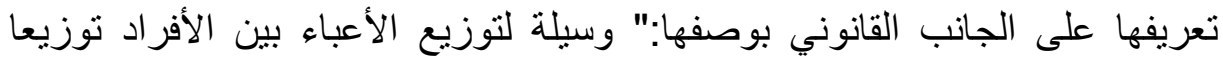

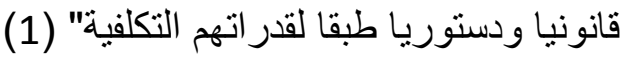

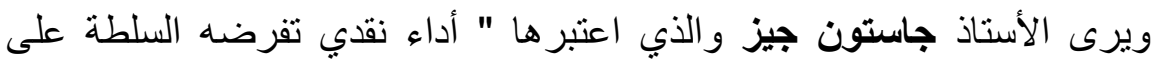

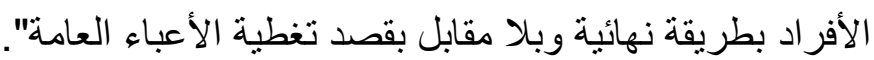

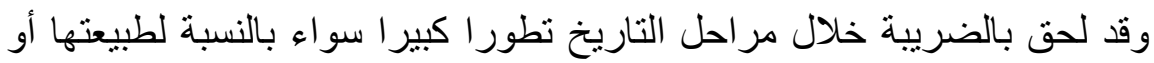

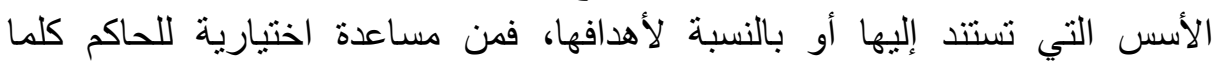

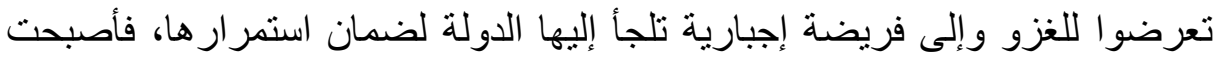

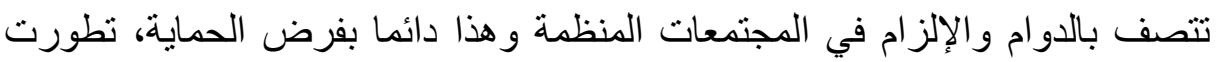


بعد ذلك هذه الفكرة باكتسابها هدفا مواليا بحتا وصارت بذللك و إضافة إلى عنصر

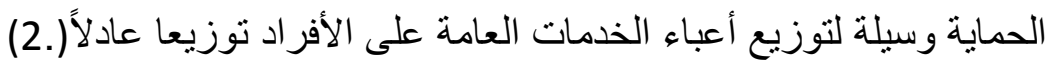

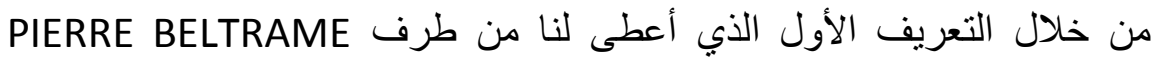

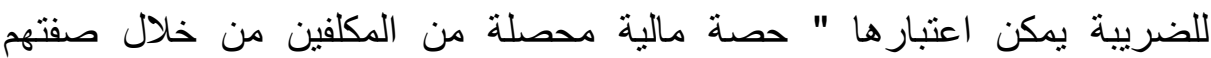

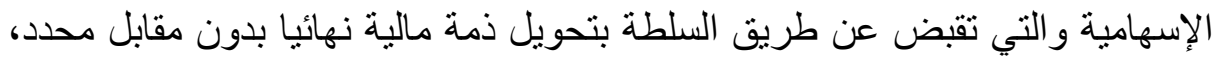

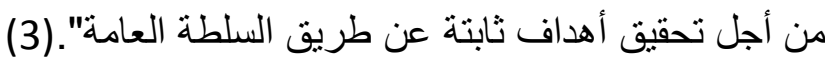
فمهما يكن من أمر التباين في الاتجاهات بشأن تحديد مفهوم معاصر للضريبة

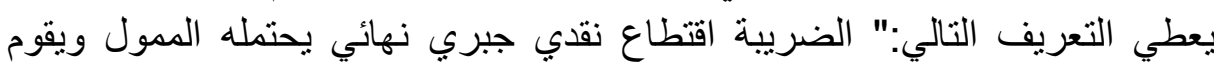
بدفعه بال مقابل وفقا لمقدرته التكليفية مساهمة في الأعباء العامة ولتخل السلطة لتحقيق

أ هداف معينة". (4) ثنانيا :مقومات الضريبة

يمكننا من خلال التعاريف السابقة الذكر حصر مقومات الضريبة فيما يلي:

1. الضريبة إجبارية وبصفة نهائية:

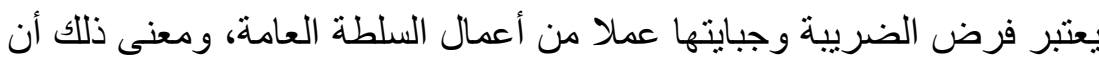

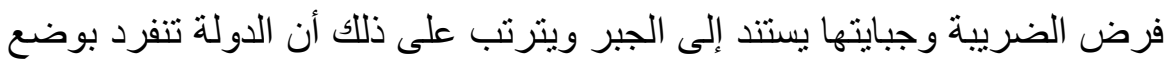
النظام القانوني للضريية، فهي التي تتحدد دون اتفاق مع المكلف و عاء الضريبة

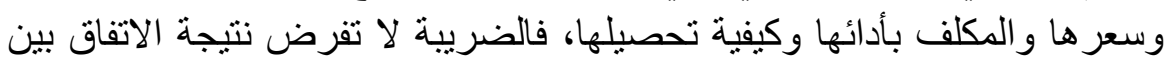
الدولة و المكلف بها. ويترتب أيضا على استناد الضريبة إلى الجبر، أي أن الدولة عند امتناع

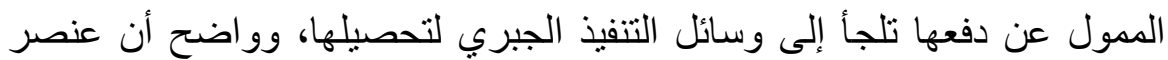
الجبر الذي تستند إليه الضريبة هو الذي يميزها عما يدفعها الفرد من ثمن مقابل

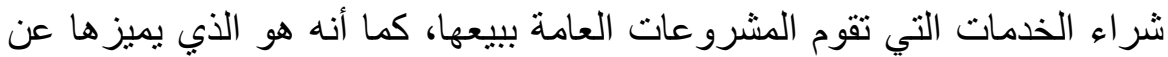

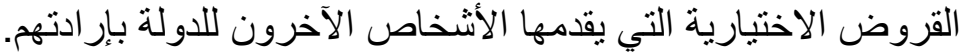

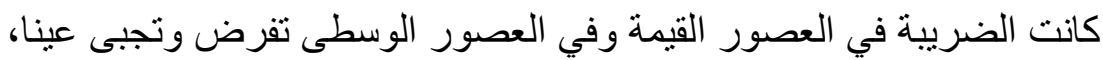
وذلك جفي شكل التزام الأفراد بتقديم عمل معين (وهو ما يعرف السخرة أو تسليم أثياء أو جزء من المحصول، كما كان الثأن في ظل الإمبر اطورية الرومانية)

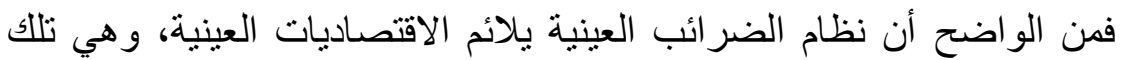

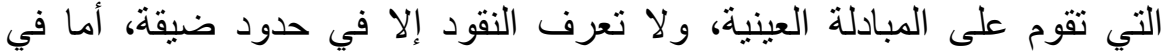

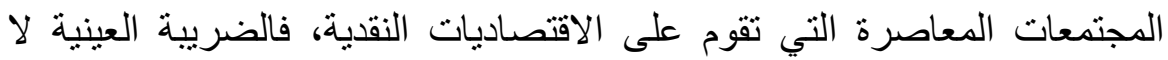
تطبق، ونجد أن الضرائب النقدية تشكل القاعدة العامة للضريبة، ذلك أنها

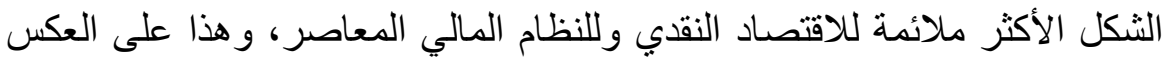

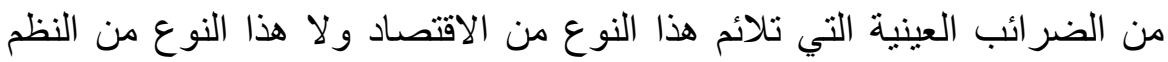
المالية وذلك للأسباب التالية(5)

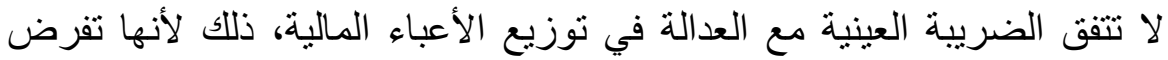

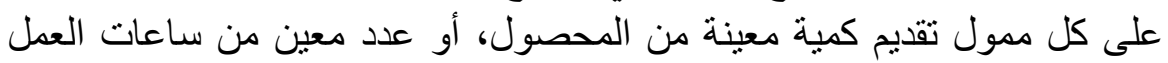


تسقط من حسابها اختلاف تكاليف الإنتاج من منتج إلى آخر واختلاف قدرة الأفراد على تحمل العمل. تستلزم الضريية العينية قيام الدولة بتكاليف مرتفعة عن تلك التي تتطلبها الضريبة النقية، وذللك بسبب ما تتحمله الدولة من نفقات جمع المحاصيل ونقلها وتخزينها،

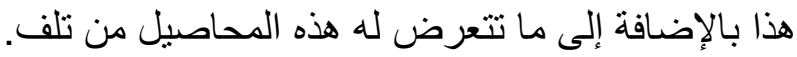

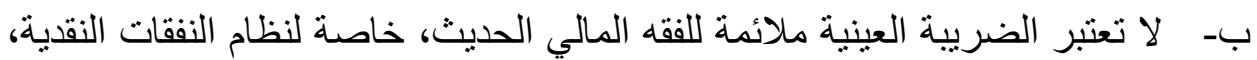

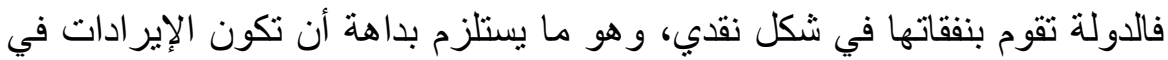

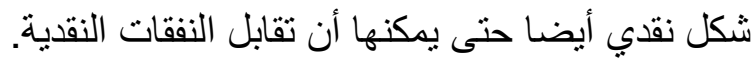
3. الضريبة بدون مقابل:

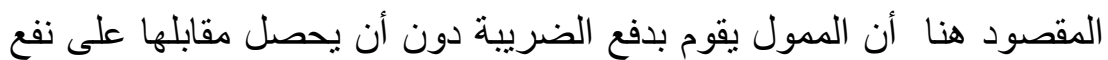

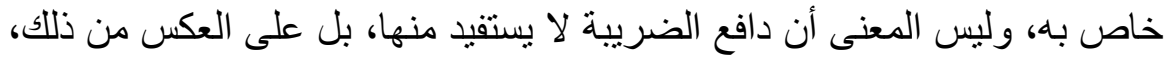

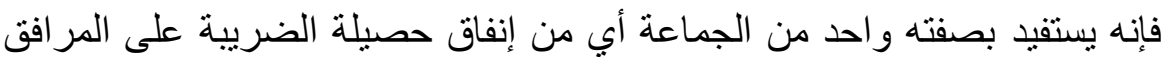

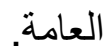

إن الممول الذي يدفع الضريبة لا يستفيد من الخدمات العامة بطريقة فردية،

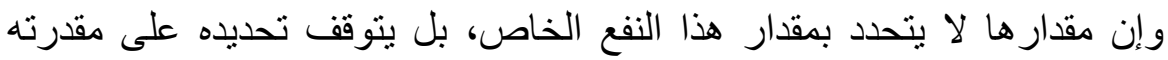

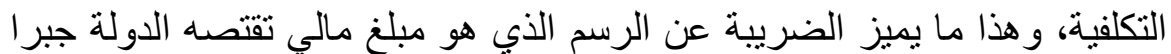

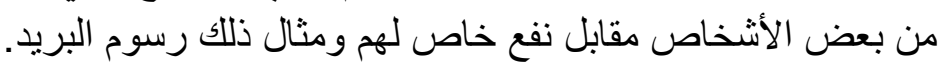

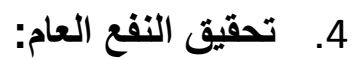

رأينا سابقا أن الدولة لا تفرض الضرن الضريبة مقابل نفع خاص تقدمه للمكلف بأدائها

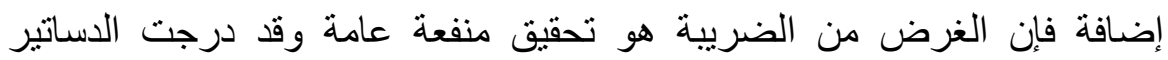

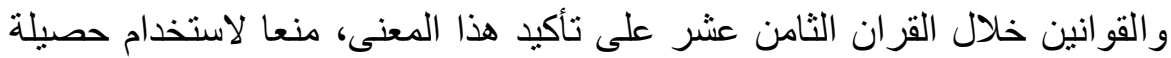

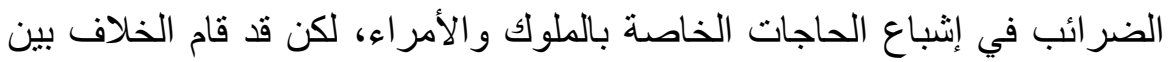
الاقتصاديين حول تحديد المقصود بالمنفعة العامة.

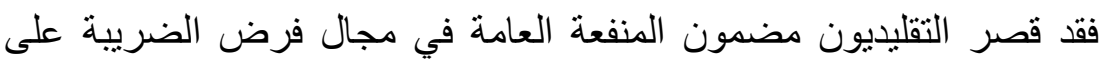

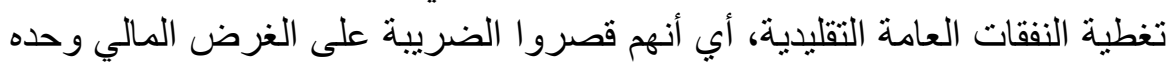

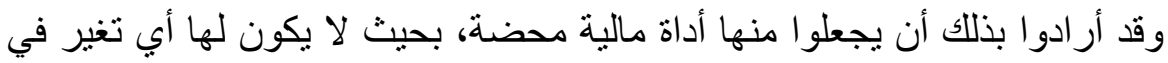

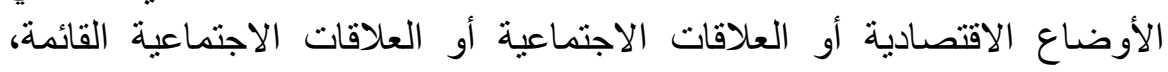

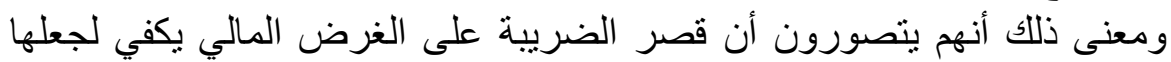

المؤكد أن هذا المعنى الضيق لفكرة حياد الضريبة لا يضمن هذا الحياد وذللك لسببين:

أولهما: أن الضريبة هي تحويل لمبلغ نقدي، وعلى ذلك فإنها لا يمكن أن

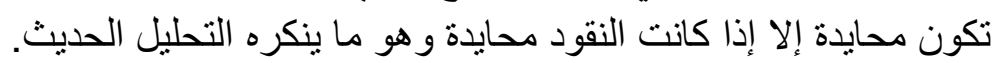

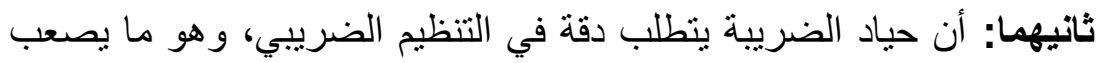

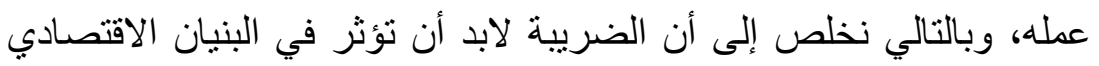

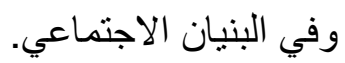
أما ظعن موقف الاقتصاديين الحديثين فإنّهم لا يتصورون وللأسباب السابقة الذكر

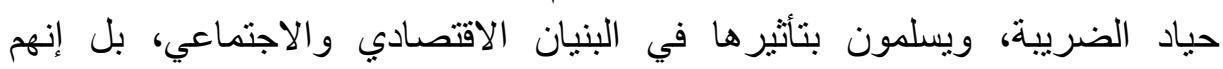




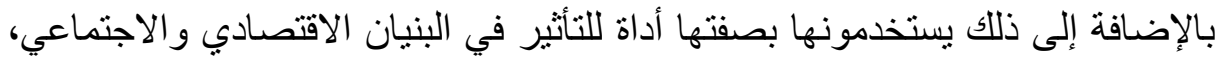

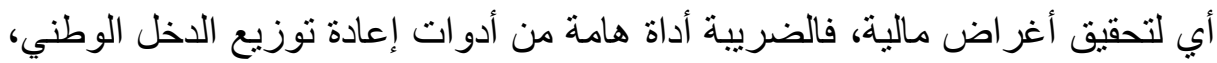
أي أنها تشكل أداة هامة من أدوات السياسة الاقتصادية والسياسة الاجتماعية.

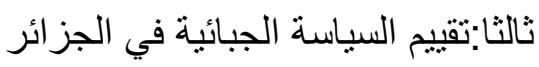

لعل أهم الصعوبات التي تواجه الإدارة الضريبية الئرية اليوم هي عدم مواكبتها لثورة الإعلام والاتصال والتجارة الالكترونية التي أصبحت تشكل تحديا

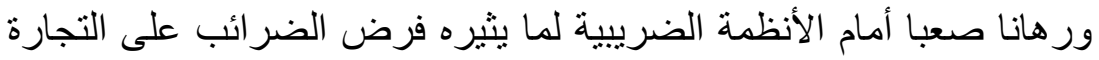
الالكترونية مع مشكلات نتيجة للنقائص و الصعوبات التيات التي تعاني منها الإدارة

نقص الإمكانيات المادية و البشرية اللازمة لأداء مهامها.

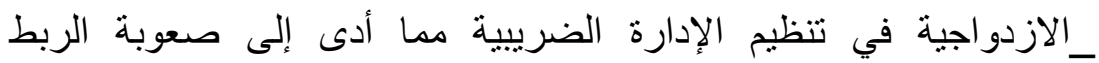

$$
\text { و التنسيق }
$$

مع مصالحها الخارجية.

ــعدد المصالح الخارجية للإدارة الضريبية فيما يخص تسيير الملف الجبائي للمكلف بالضريبة وذلك حسب نوع كل ضريبة مما أدى إلى تقدير ات مختلفة بالنسبة المكلف بالضربة . _عدم استقرار القوانين و التشريعات الضريبية نتيجة للتعديلات المستمرة بموجب قوانين المالية مما يصعب على أعوان الإدارة الضريبية و المكلفين بها إنباعها . بموجا _عدم تزويد غالبية الإدارة الضريبية بنظام الإعلام الآلي وتكنولوجيا الإعلام والاتصال مما يجعل الإدارة الضريبية أمام تحديات صعبة في الإدية المرحلة

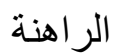
_عدم مسايرة التشريعات الحالية والإدارة لثورة الإعلام و الاتصال وطبيعة التجارة الإلكترونية التي يصعب مر اقبتها لكثرة التهرب الضرئ التريبي فيها.

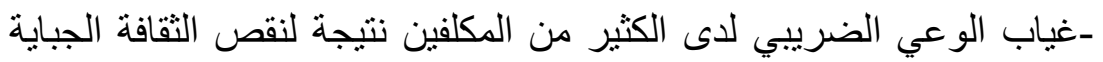

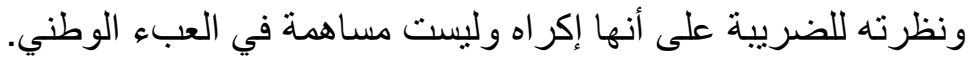

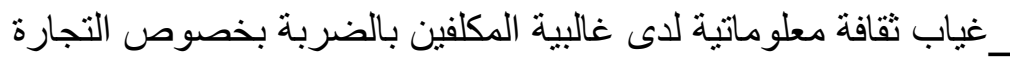

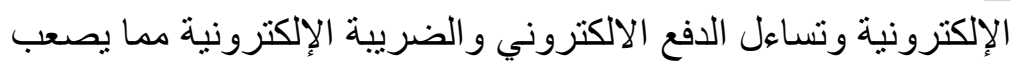

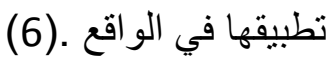

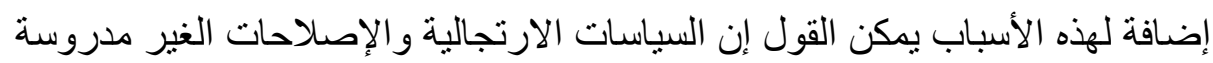

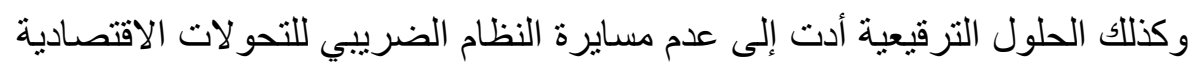
المحور الثاني: هياكل الإدارة الضريبية بعد الإصلاحات

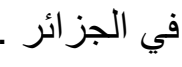

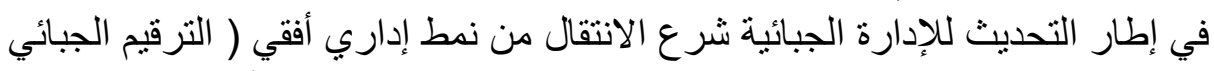

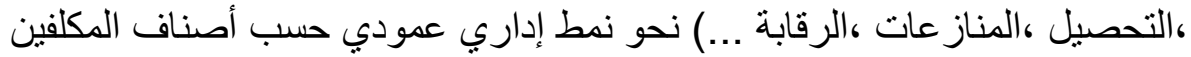

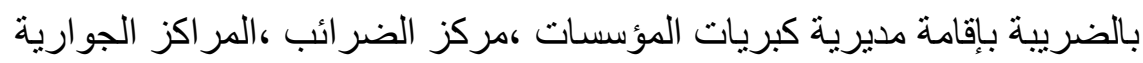
للضر ائب حيث تتولى مديريات كبريات المؤسسات ملفات المكلفين الكبار (7).بينما تتولى مر اكز الضر ائب تسيير المؤسسات الصغيرة و المتوسطة و المهن الحرة بدلات من 
المفتشيات و القبضات أما المكلفون الصغار المسيرون وفق النظام الجزافي سيلحقون

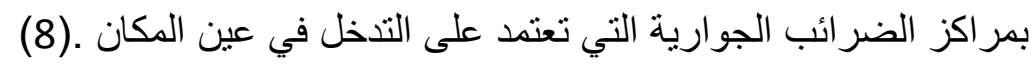

أولا :مديرية كبريات المؤسسات

أنشأت مديرية كبريات المؤسسات بموجب المبرية المرسوم التنفيذي 02 -03 المؤرخ

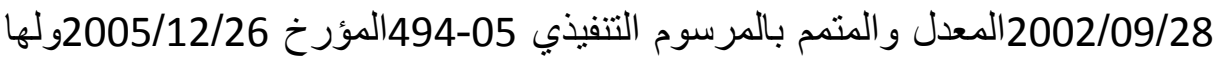
مجموعة صلاحيات على المستوى الوطني ومكلفة بنسيير كل المهام معا :الوعاء

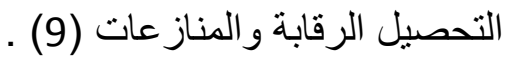

تعين الهيئة المكلفة بالمؤسسات الكبرى كمحل إيداع التصريحات الجبائية وتسديد الضر ائب و الرسوم بالنسبة إلى :الأشخاص المعنوية أو تجمعات الأشخاص المعات المعنوبين

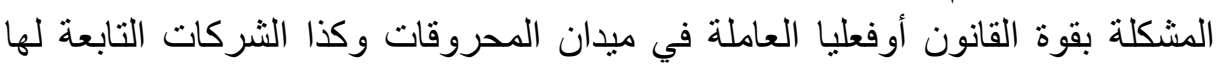

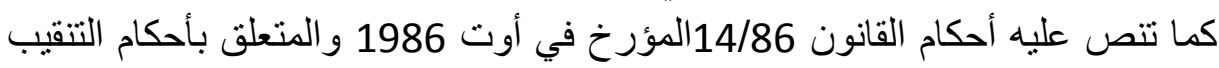

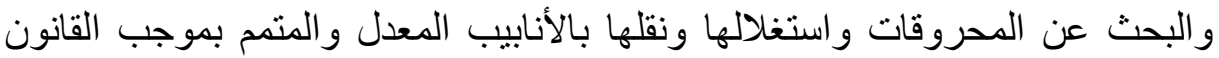

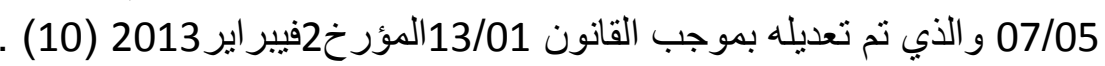
-شركات رؤوس الأموال والثركات الأشخاص التي اختارت الثنارت هذا النظام الجبائي

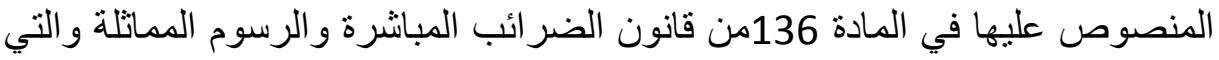
يساوي أو يفوق رقم إعمالها في نهاية السنة المالية مائة مليون دينار جزائري البرائ البرمي

(11).(100000000)

وتتبع معظم دول العالم هذه الطريقة لعدة أسباب منها:

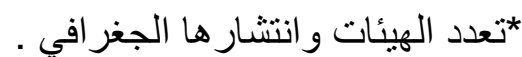
*تعدد الأنشطة أو المساهمة في معاملات تطرح مشاكل معقدة وتفسيرات جديدة للقانون *قيامها بعمليات هامة في الخارج *تحقيقها لرقم أعمال مرتفع في إطار النشاط المهني *|ستعمال أدوات تمويل معقدة (12)*لجوؤها إلى مستشارين ضريبيين محترفين

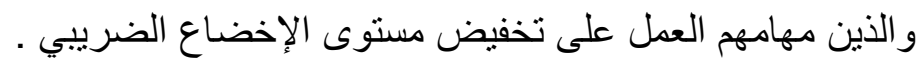

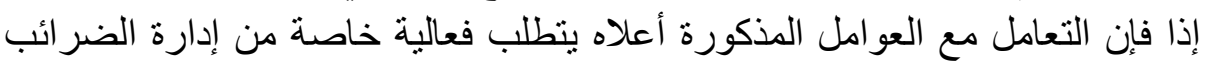

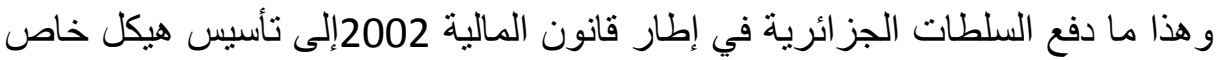

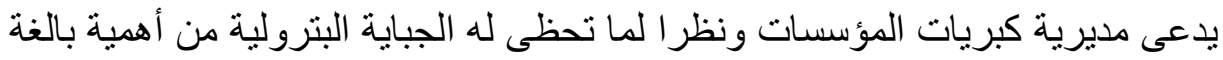
في الإيرادات الجبائية خصصت لهات من خلال مديرية كبريات المؤسسات مديرية

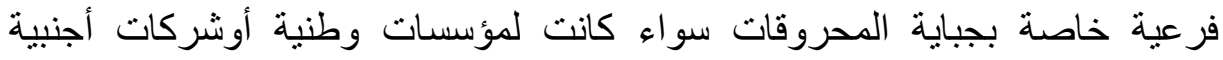

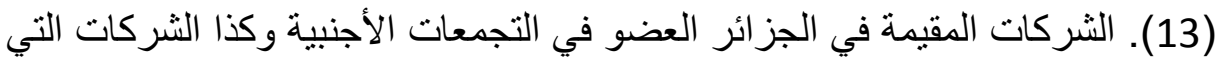

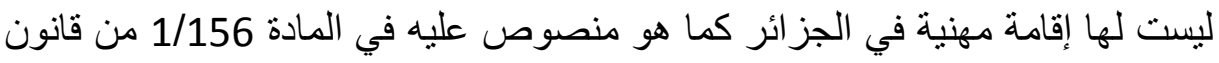

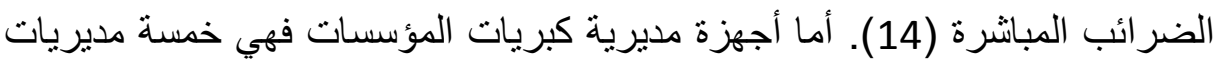


المديرية الفرعية لجباية المحروقات و المكلفة بجباية المحروقات لسيما بتسيير

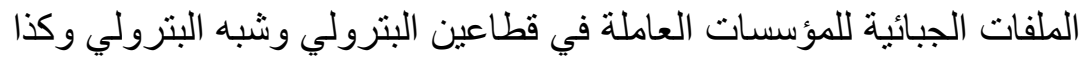

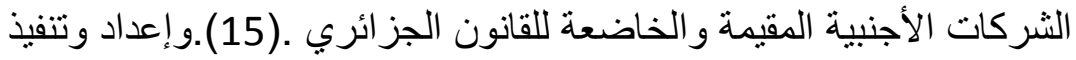

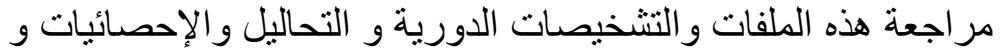
تحضير مخططات العمل . وتتكون هذه المديرية الفرعية من ثناث مكاتب :

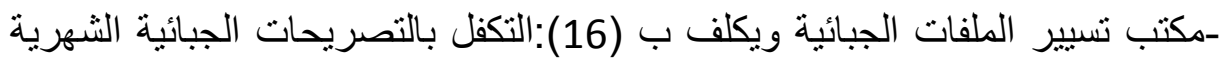

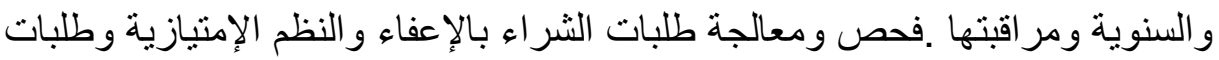

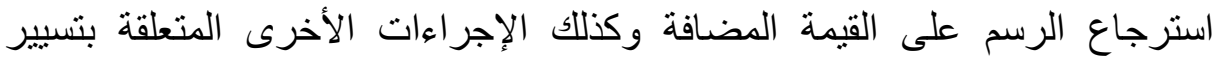
الملفات الجبائية .(17) ويصم هذا المكتب من :.-مصلحة مر اجعة المؤسسات البترولية

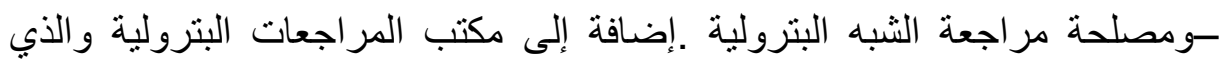

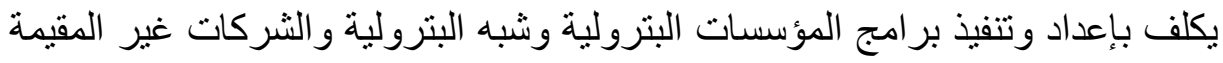

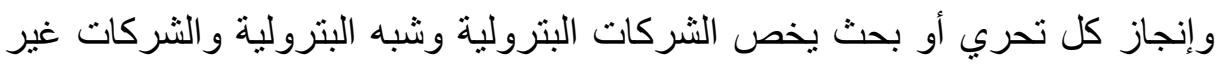
المقيمة .ويضم هذا المكتب مصلحتين هما:-مصلحة مراجعة المؤسسات البترولية ومصلحة المر اجعة المؤسسات الثبه البترولية (18)

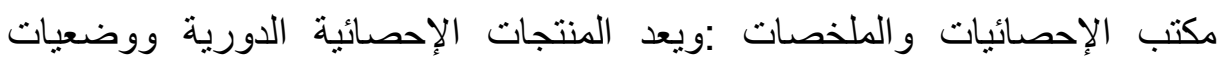

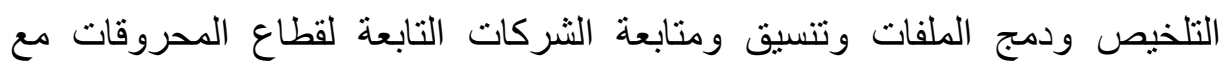

المديرية الفرعية للتسيير :وتسير ملفات الجبائية الخاضعة للقانون العام وكذا

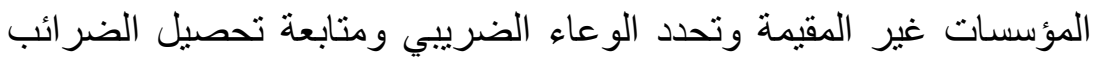

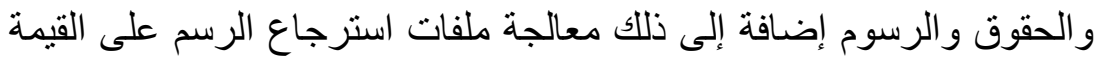

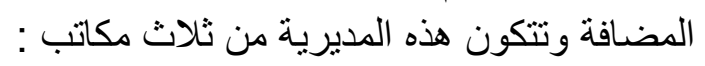

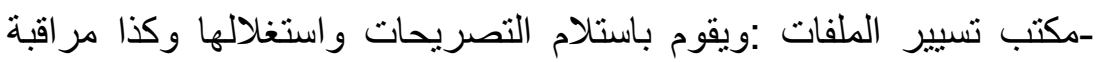

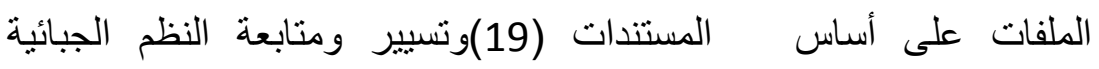

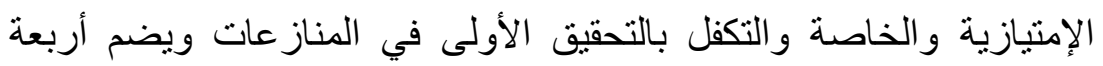

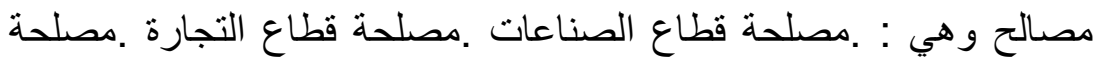

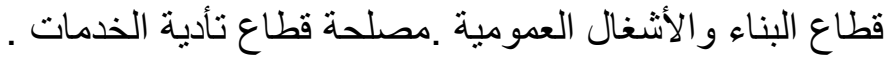
-مكتب التدخلات ودعم التسيير (20):ويقوم بمتابعة التكفل بمقارنة المستندات ومعالجة الجاتة طلبات إسترجاع الرسم على القيمة المضافة و القيام بالتنخلات المنتظمة و المعاينات في عين المكان ويضم مصلحتين : -مصلحة متابعة الامتيازات الجبائية واسترجاع الدفع المسبق للرسم على القيمة المضافة. ـمصلحة المعاينات ومتابعة المعلومة الجبائية. -مكتب مر اقبة التحصيل و التصفية

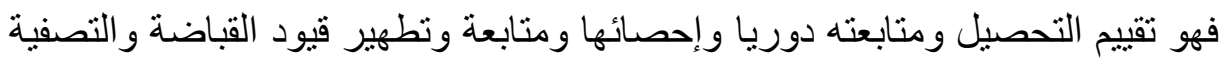

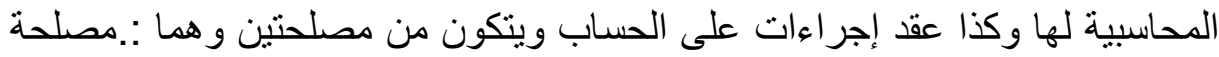

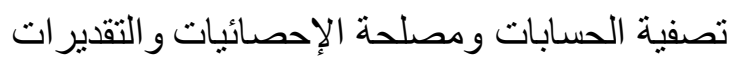

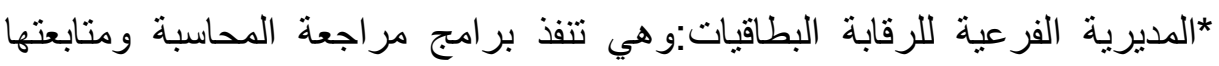
واقتراح التسجيل في البرامج السنوية للمراقبة ،والبحث عن لفية المعلومة الجبائية 
و استغلالها مع إنجاز التحقيقات والتحريات وتتكون من مكتب المراجعات ومكتب

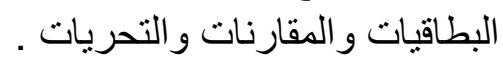

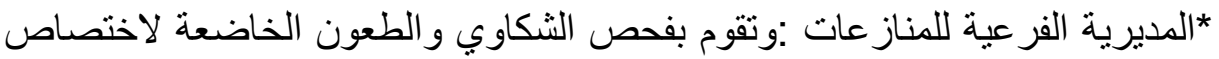
كبريات المؤسسات ودراستها و وتحضر الملفات النزاعية المتعلقة بالقضايا المقدمة

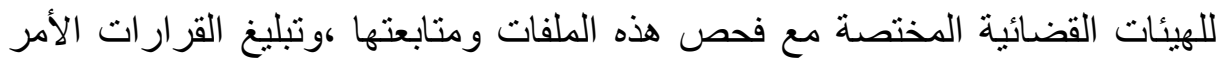
بصرفها ـوتتكون من ثلاث مكاتب و هي (21)( مكتب الثكاوي ـمكتب لجان الطعن

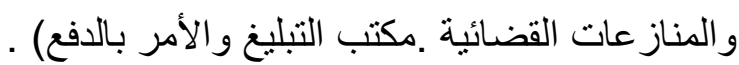

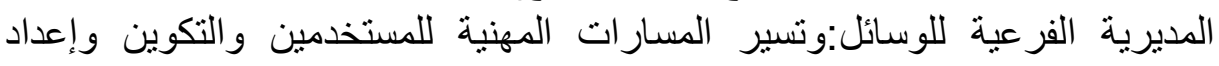

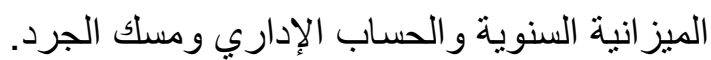

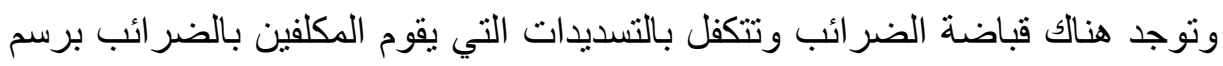

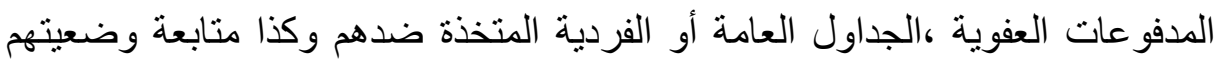

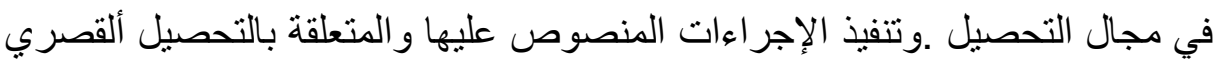

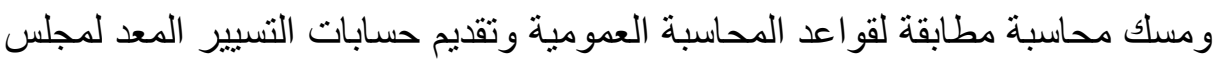

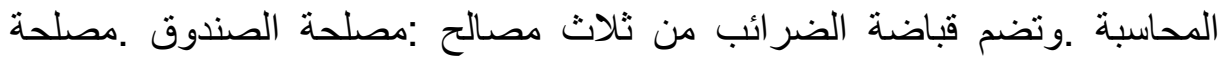

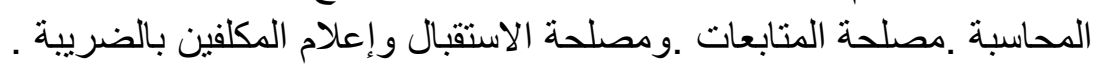

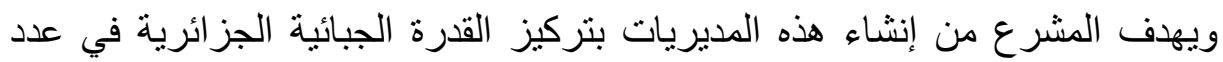

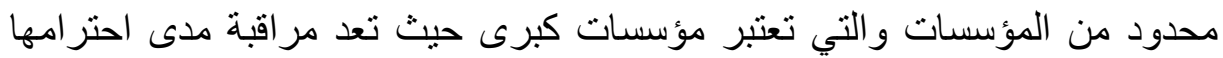

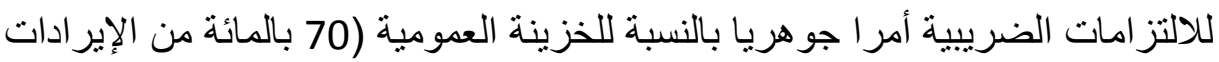

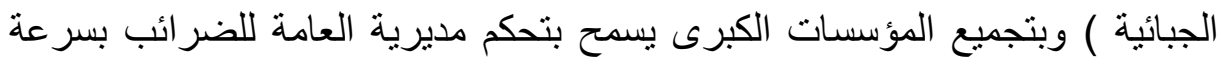

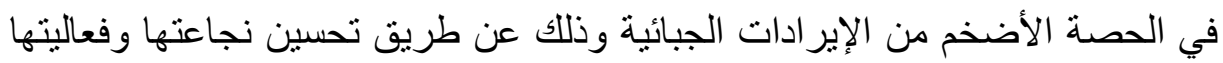

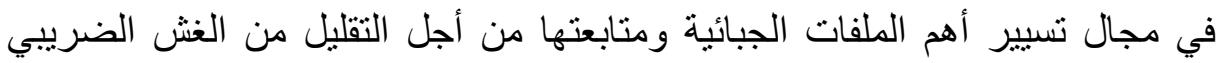

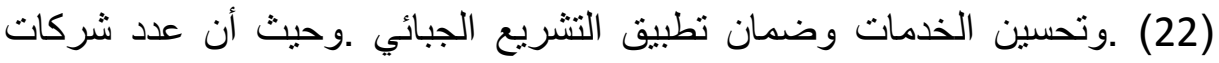
البترولية لسنة 2009135 شركة بترولية و51شركة بترولية ـ وتكلف بالمهام التالية : -في المجال الوعاء مسك الملف الجبائي لكل مكلف بالضريبة : ـالبحث عن المعلومة الجبائية وجمعها واستغلالها.

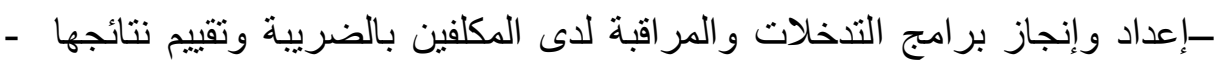

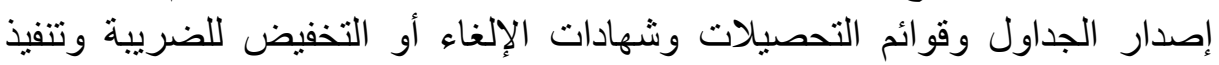

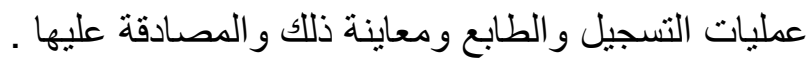
-منح الاعتمادات لصالح المكلفين المستفيدين من نظام المشتريات ولات والإعفاء من الرسم

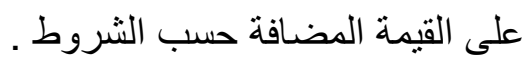
ـالتحقيق في التظلمات والشكايات ومعالجتها وضمان متابعة المنازعات الإدارية

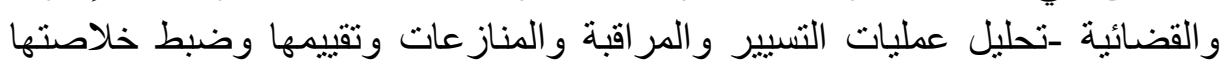

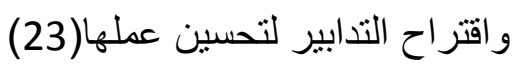

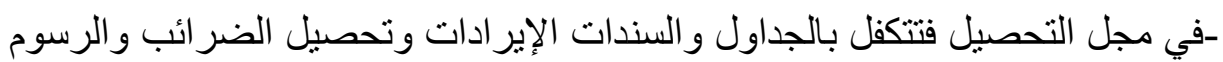

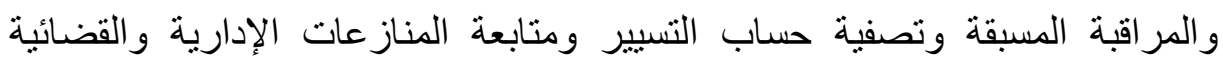

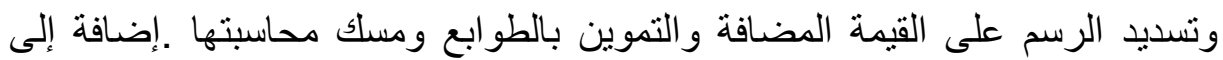


تحليل عمليات التحصيل وتقييمها وضبط خلاصنها و إقتر اح كل تدبير من شأنه تحسين

ثناتيا:مركز الضرائب:هو مكلف ب:

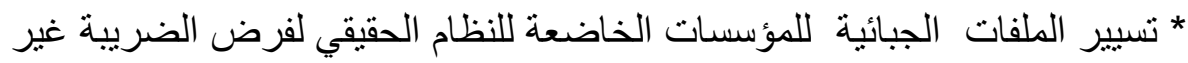

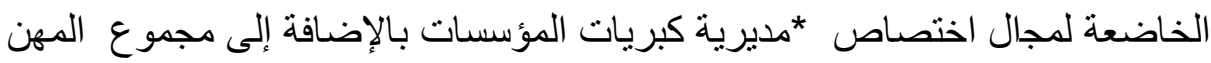

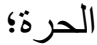

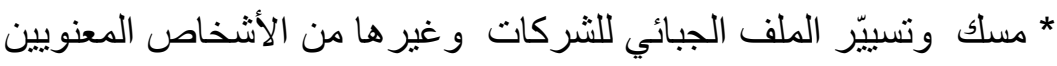

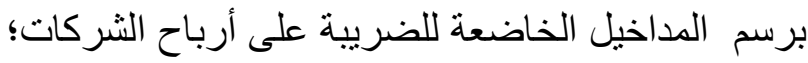

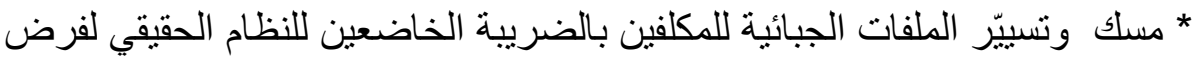

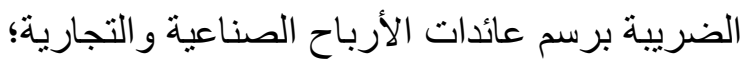
* إصدار الجداول وقوائم التحصيلات وشهادات الإلغاء أو التخفيض ومعاينتها و المصادقة عليها؛

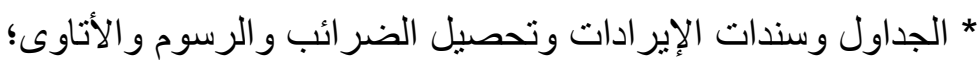

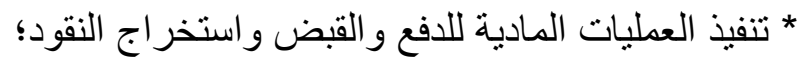
* ضبط الكتابات ومركزة تسليم القيم؛ * لقئ

* البحث عن المعلومات الجبائية وجمعها واستغلالها ومر اقبة التصريحات؛

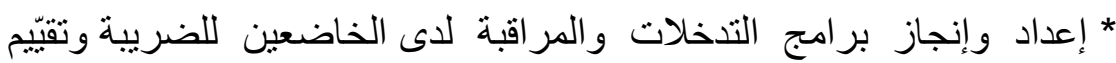
نتائجها؛ * ت تدرس الثكاوى وتعالجها؛

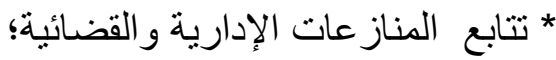

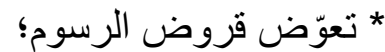

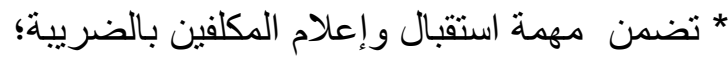

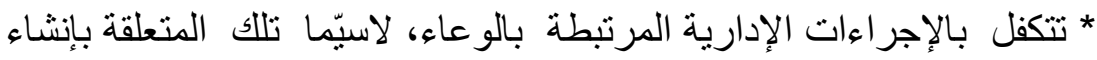
المؤسسات وتعديل نظامها

الأساسي؛ * تنظم المواعيد وتشير ها؛ *تنشر المعلومات والآراء لصالح المكلفين بالضريبة التابعين لاختصاص مر اكز

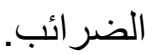
يتكون مركز الضرائب من ثلاث (03) مصالح رئيسية و قباضة ومصلحتين:

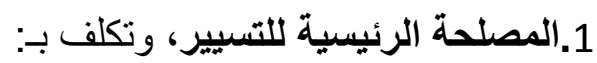

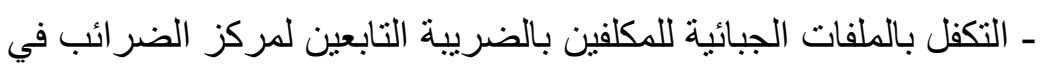

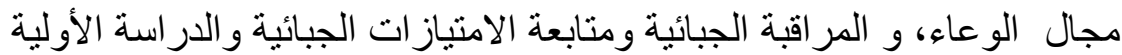
ل ل احتجاجات؛

ـ المصادقة على الجداول وسندات الإير ادات وتقد يمها لرئيس المركز للموافقة عليها، بصفته وكيلا مفوضا للمدير الو لائي للضر ائب؛

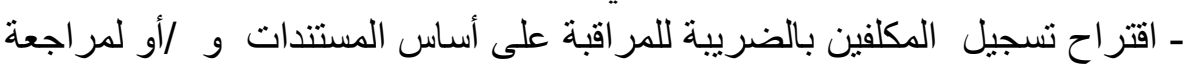

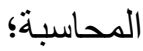
- إعداد تقارير دورية و تجميع الإحصائيات و إعداد مخططات العمل و وتنظيم الأشغال مع المصالح الأخرى مع الحرص على على انسجامها. 
تعمل على تسيير: المعار

أ) المصلحة المكلفة بجلياية القطاع الصناعي؛ ب) المصلحة المكلفة بجباية قطاع البناء والأشخال المكاعة العمومية ؛

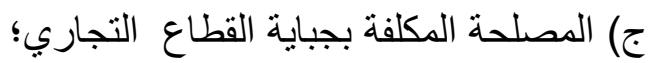

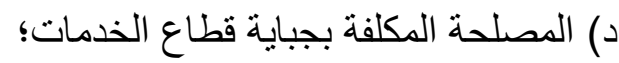
هـ) المصلحة المكلفة بجباية المهن الحرة.

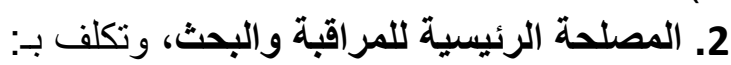
- إنجاز إجراءات البحث عن المعلومة الجبائية ومعالجتها وتخزينها و توزيعها وليها ولئها من أجل استغلالهها؛

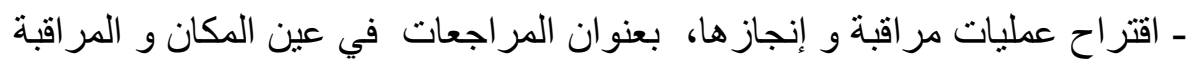

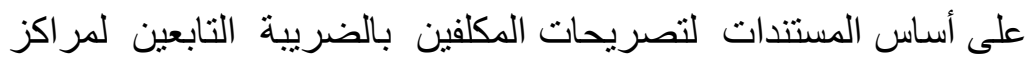

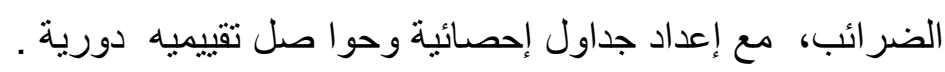

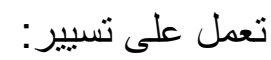

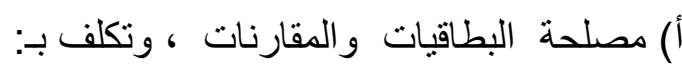

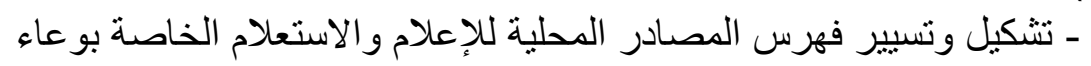
الضريية وكذا مر اقبتها وتحصيلها؛ - مركزة المعطيات التي تجمعها المصالح المعنية ، وتخزينها و واستردادها من أجل استغلالها؛

ـ التكفل بطلبات تعريف المكلفين بالضريبة.

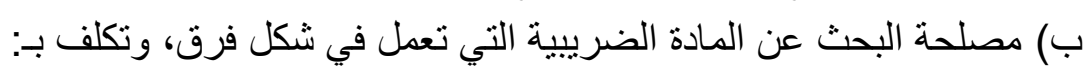

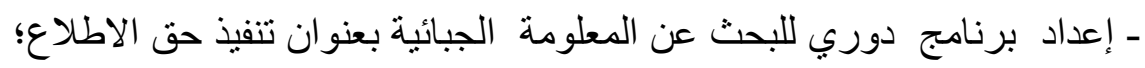

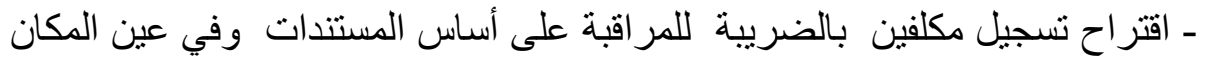

انطلاقا من المعلومات و الاستعلامات المجمعة مئرة

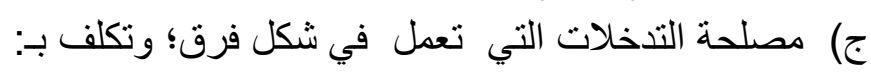

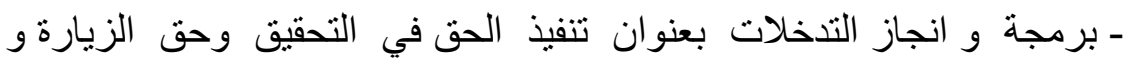

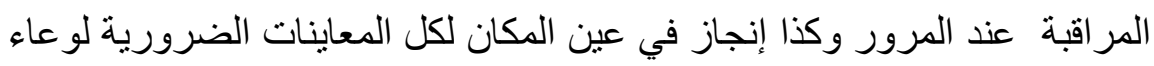

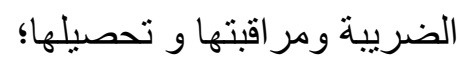
ـ اقتراح مكلفين بالضريبة لمر اجعة محاسبتهم أو للمر اقبة على أساس المستندات

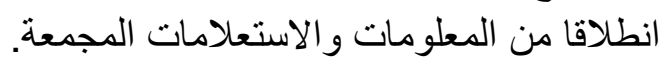

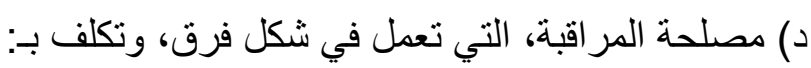

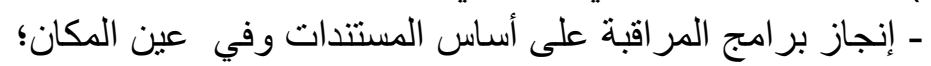

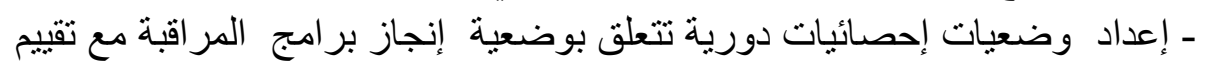
مردودها. 3. المصلحة الرئيسية للمناز عات وتكلف بـ:

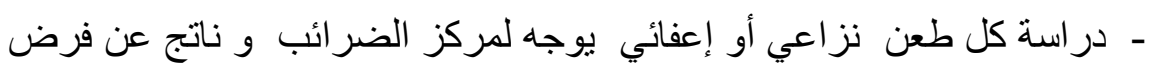

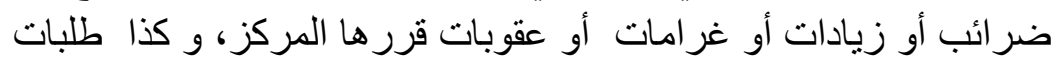

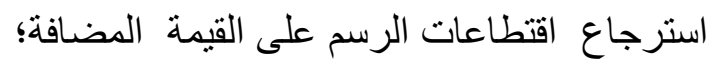
- متابعة القضايا النزاعية المقدمة إلى الهيئات القضائية. 
تعمل على تسيير:

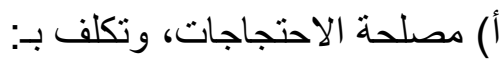

- دراسة الطعون المسبقة التي تهدف إلى إلغاء أو تخفيض فرض ضات ضر ائب أو

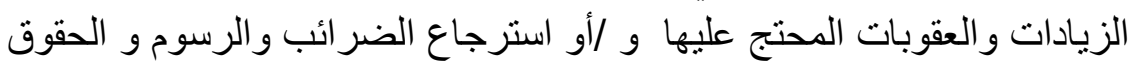

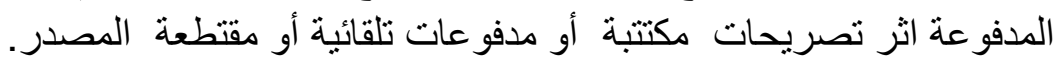

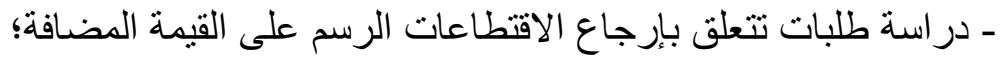

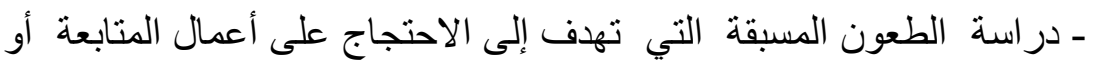

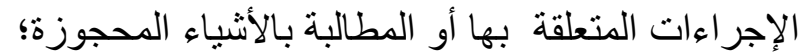
- معالجة مناز عات التحصيل.

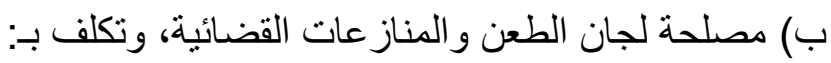

ـ در اسة الطعون التابعة لاختصاص لجان طعن الضر ائب المباشرة و والرسم على الثى

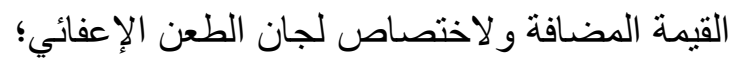

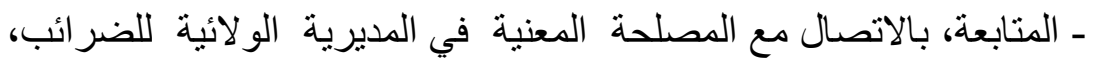
للطعون و الثكاوى المقدمة للايئات القضائية؛

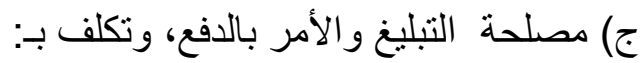

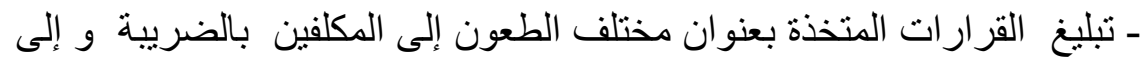

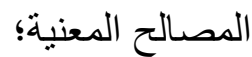
ـالأمر بصرف الإلغاءات و التخفيضات المقررة مع إعداد الثهادات المتعلقة بها؛

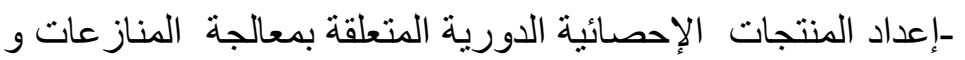

تبليغها للمصالح المعنية.

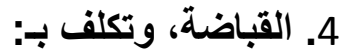

ـ التكفل بالتسديدات التي يقوم بها المكلفون بالضريبة بعنوان التسديدات التلقائية

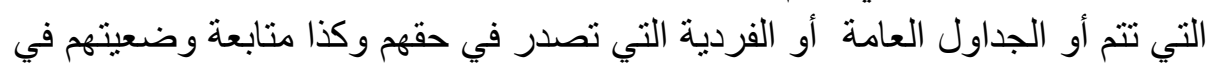

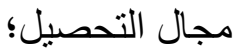
ـ تتفيذ التدابير المنصوص عليها في التشريع و التنظيم الساريين المفعول

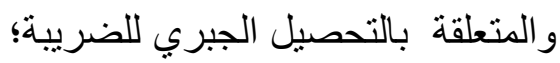
- مسك محاسبة المطابقة لقو اعد المحاسبة العامة وتقديم حسابات التسبير المعدة إلى مجلس المحاسبة. تعمل على تسير:

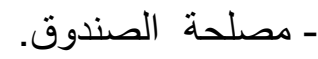
- مصلحة المحاسبة.

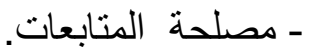
تتظم مصلحة المتابعات في شكل فرق المات . 5. مصلحة الاستقبال والإعلام، تحت سلطة رئيس المركز، وتكلف بـ: ـ تتظيم استقبال المكلفين بالضريبة و إعلامهم؛

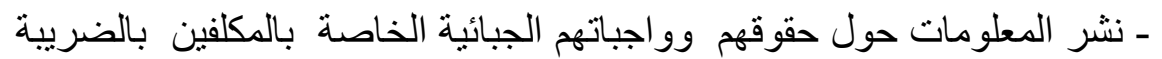
التابعين لاختصاص مركز الضر ائب.

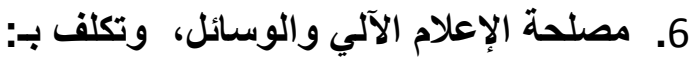

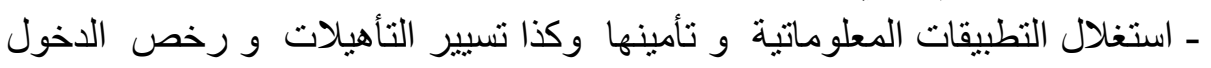


المو افقة لها؛

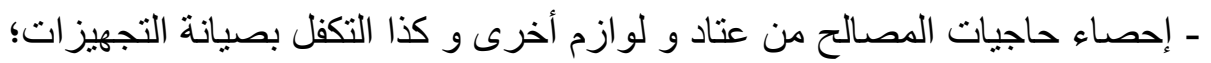

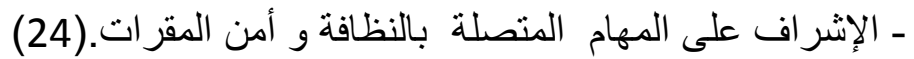

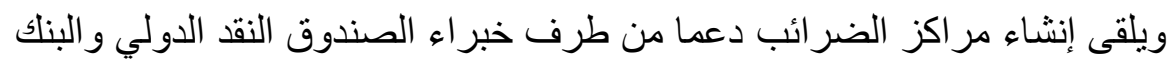

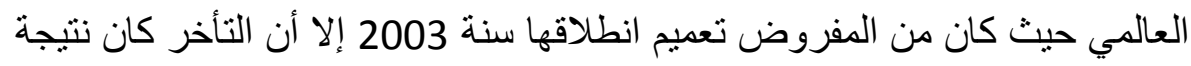

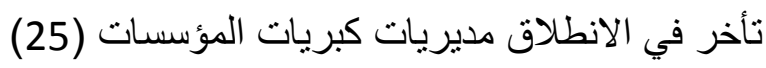

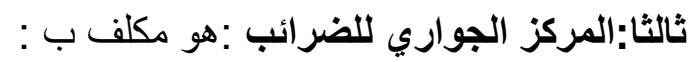

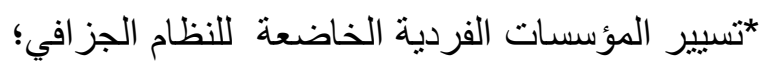
* تسيير المستثمر ات الفلاحية؛

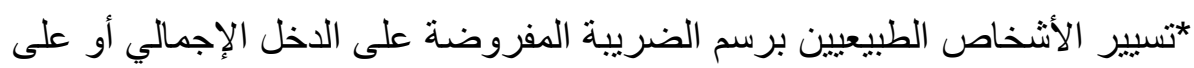

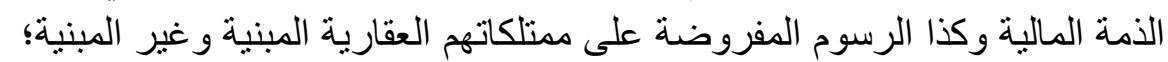

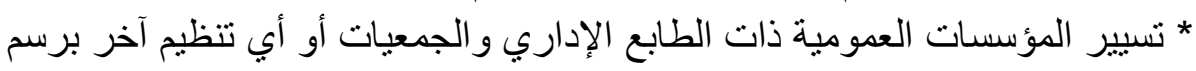

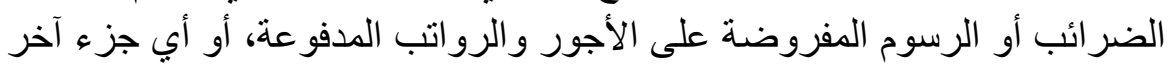

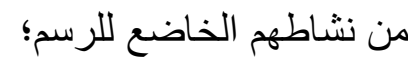

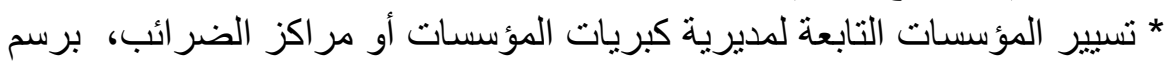

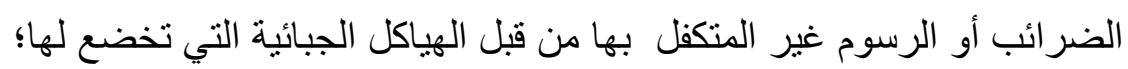

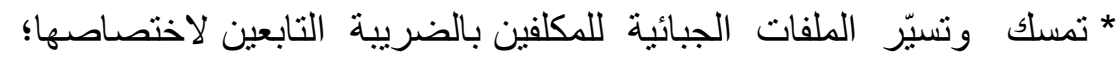

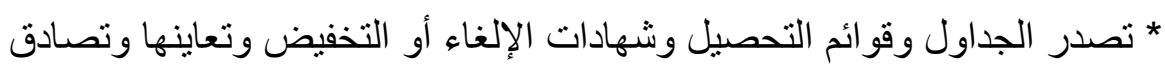
عليها؛ * تتكفل بالجداول وسندات الإيرادات وتحصيل الضر ائب و الحقوق و الرسوم

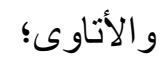

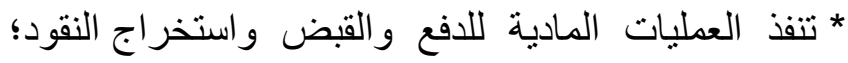

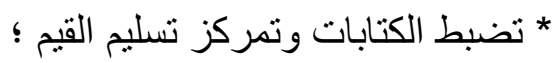

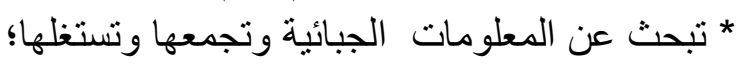
*تر اقب التصريحات وتتظم التذخلات؛ "تدرس الثكاوى وتعالجها؛ *تتابع المناز عات الإدارية و القضائية؛

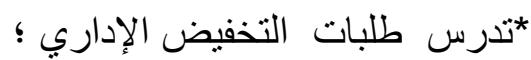
* تضمن مهمة استقبال و إعلام المكلفين بالضريبة الإدئ * تتكلل بالإجراءات الإدارية المرتبطة بالوعاء لاسيّما تلك المتعلقة بإنشاء

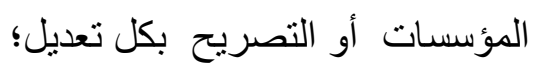

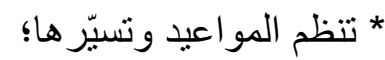

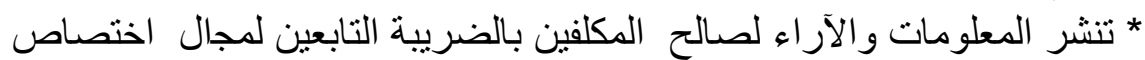
المر اكز الجوارية للضر ائب. يتكون المركز الجواري للضر ائب في ثلاث (03) مصالح رئيسية و قباضة ومصلحتين . 
1. المصلحة الرئيسية للتسيير، وتكلف بـ:

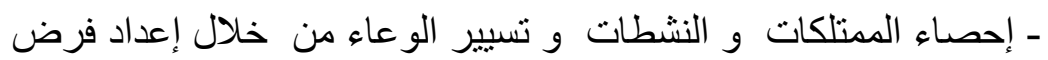

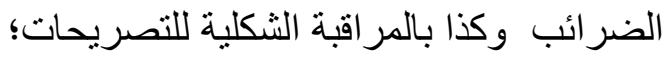

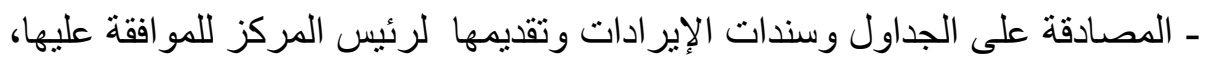
بصفته وكيلا مفوضا للمدير الو لائي للضرائب؛ الإبرات الضبات

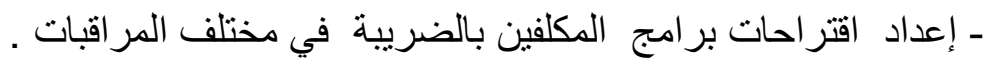
تعمل على تسيير: أ) مصلحة جباية النشاطات التجارية و الحرفية، وتكلف بـ:

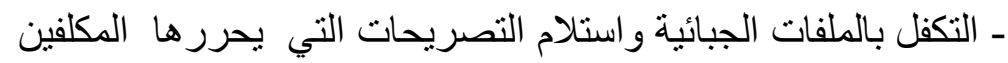
بالضريية المتابعون حسب نظام الضريبة الجزافية الوحيدة، و كذا إعداد العقود المتصلة بها؛ ـ المر اقبة الثكلية للتصريحات و اقتر اح ملفات مكلفين بالضريية للمر اقبة على أساس

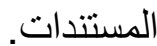

ب) مصلحة الجباية الزراعية، و وتكلف بـ:

ـ التكفل بالملفات الجبائية للمزارية اعية وعين و المربين وكذا استقبال و واستغلال

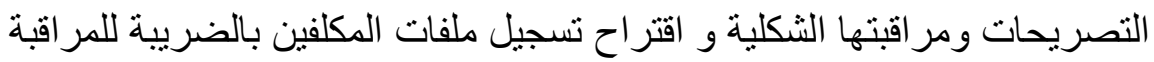

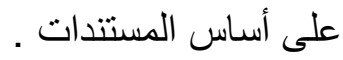

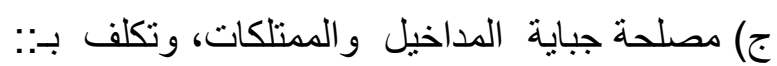

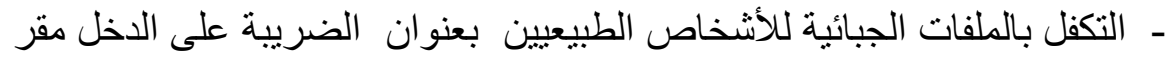

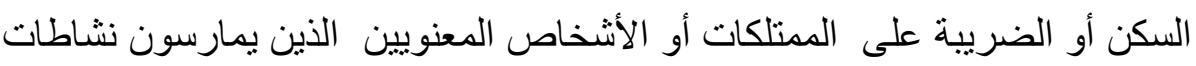

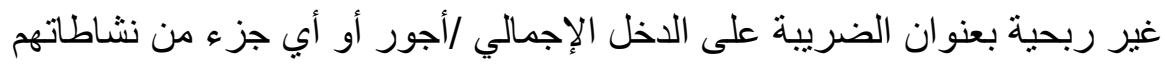
يمكن فرض الضريبة عليه؛ ـ المر اقبة الثكلية للتصريحات و اقتراح التسجيل، عسب التبل الحالة في برنامج المر اقبة على أساس المستندات و /أو المر اجعة المعمقة للوضعية الجبائية الثناملة.

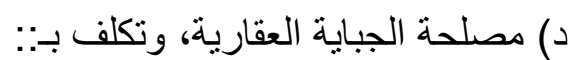

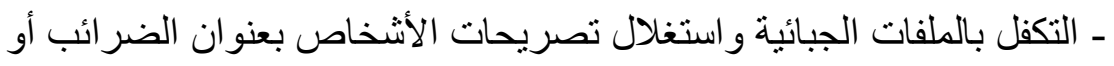
الرسوم المفروضة على الممتلكات العقارية؛

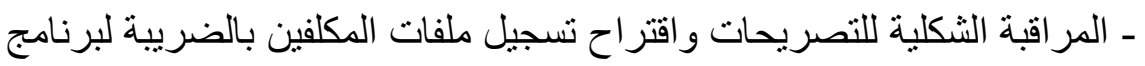
المر اقبة على أساس المستندات أو على أساس المر اجعة المعمقة للوضعية الجبائية الثناملة.

2. المصلحة الرئيسية للمر اقبة و البحث، وتكلف بضمان:

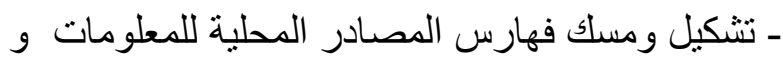

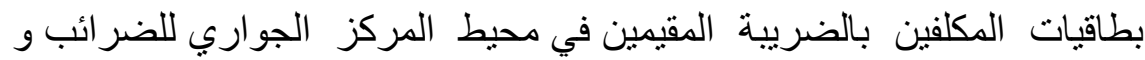

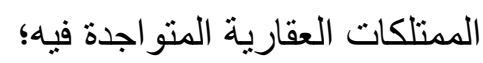
ـ متابعة تنفيذ بر امج المر اقبة على أساس مستندات التصرئه فيحات و البحث عن المادة الخاضعة للضريبة وتقييم نشاطات المصالح المعنية. تعمل على تسبير: أ) مصلحة البطاقيات و المقارنات، وتكلف بـ بـات:

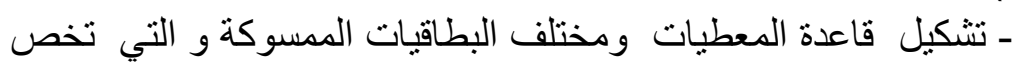




$$
\text { الوعاء و المر اقبة و التحصيل الضريبي وتنبيرها، }
$$

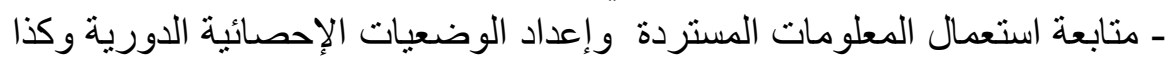

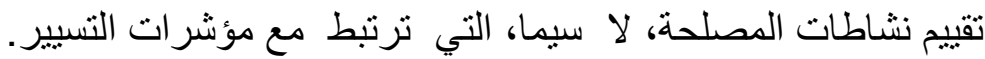

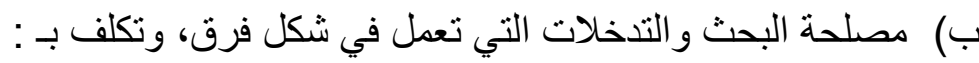

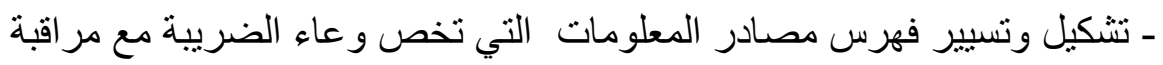
الضريبة و تحصيلها. ـ تتفيذ البر امج الدورية للبحث عن المعلومة الجبائية بعنوان حق الاطلاع؛

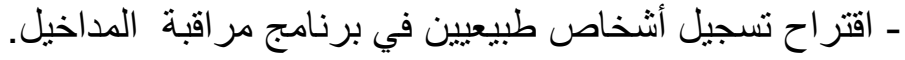

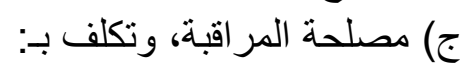
ـ تنفيذ البر امج المقررة بعنو ان المر اقبة على أساس المستندات للتصريحات؛

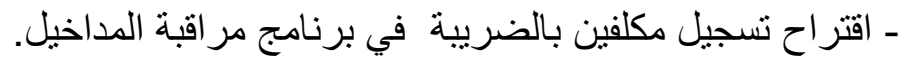

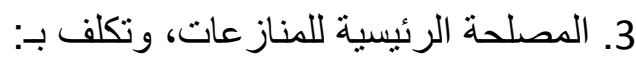

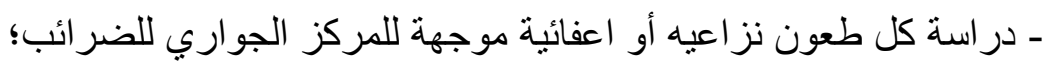

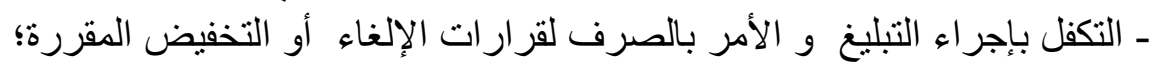
- متابعة القضايا النز اعية المقدمة أمام الهيئات القضائية.

$$
\text { أ) مصل على تسبير: الاحتجاجات، وتكلف بـ: }
$$

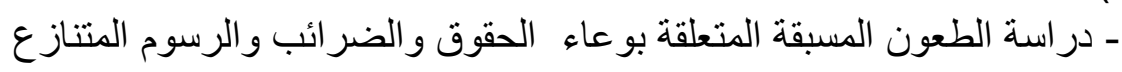
ـ دراسة الطعون المسبقة التي تهدف إلى الاحتجاج على أعمال الملاحقات أو الو الماء

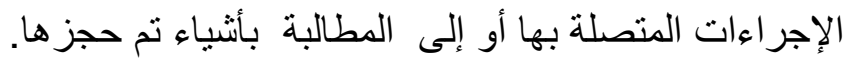

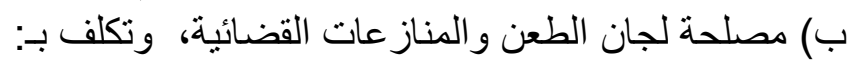

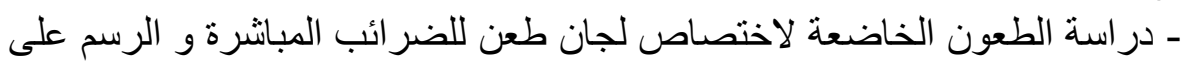
القيمة المضافة ولجان الطعن الإعفائي؛

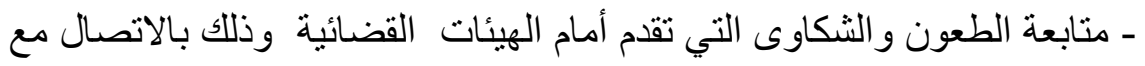

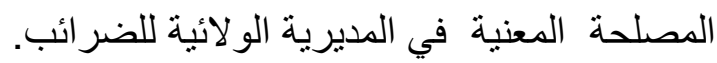

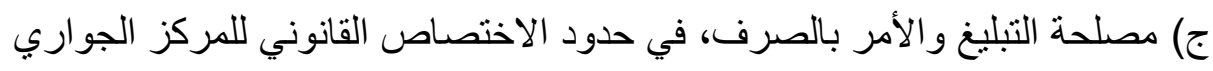

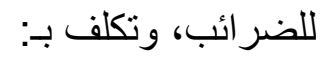
ـ تبليغ القرارات المتخذة في مجال مختلف الطعون إلى المكلفين بالضريبة و إلى الى

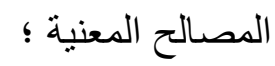
ـ الأمر بصرف الإلغاءات و التخفيضات الممنوحة و إعداد الثهادات المتصلة بها؛

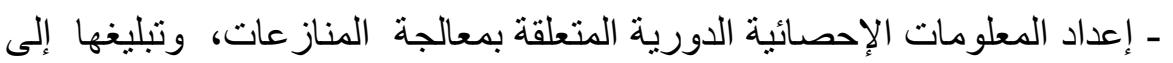
المصالح المعنية للتكفل بها. 4-مصلحة المتابعات، وتكلف بـ:

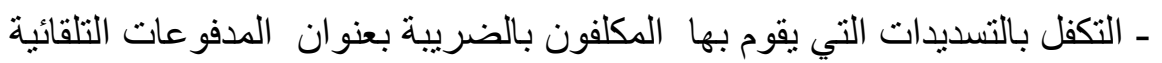

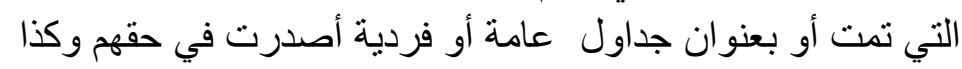

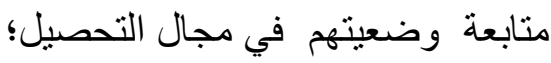
ـ تنفيذ الإجراءات المنصوص عليها في التشريع والتنظيم الساريين المفعول والمتعلقة 


$$
\text { بالتحصيل الجبري للضريبة؛ }
$$

- مسك محاسبة مطابقة لقو اعد المحاسبة العامة وتقديم حسابات التسبير المعدّة إلى الى

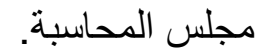

تعمل على تسيير:

أ) مصلحة الصندوق؛

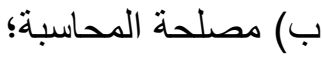

ج) مصلحة المتابعات.

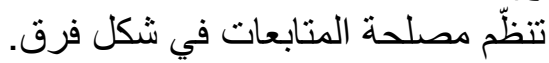

5. مصلحة الاستقبال والإعلام، وتكلف بـ فئ:

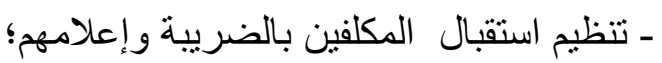

ـ نشر المعلومات حول الحقوق و الواجبات الجبائية للمكلفين بالضريية التابعين

$$
\text { لل كركز الجواري للضر ائب. }
$$

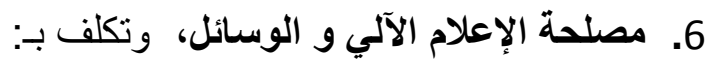

ـ استغلال التطبيقات المعلوماتية و تأمينها، وكذا تسيير التأهيلات و رخص الاخدول

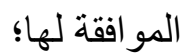

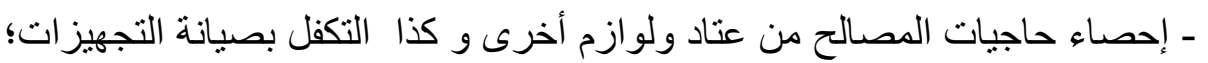

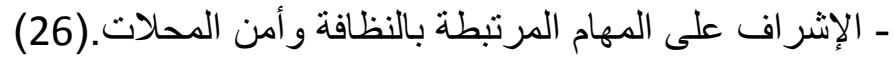

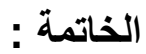

رغم الجهود المبذولة لتحسين أداء الإدارة بصفة عامة والأموال الكبيرة التي صرفت ولازالت تصرف من طرف الدولة الجزائرية وهذا بغية عصرنه الإدارة لتقريب هذه

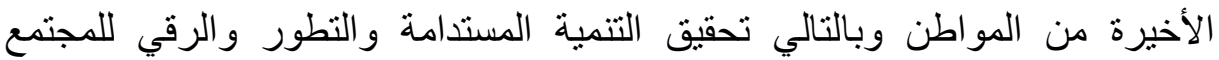

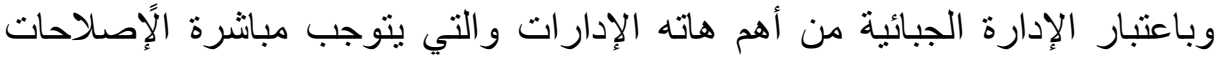

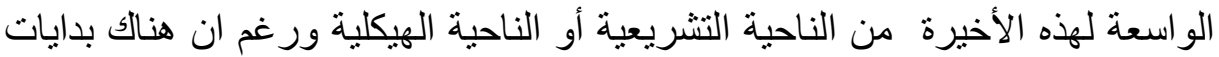

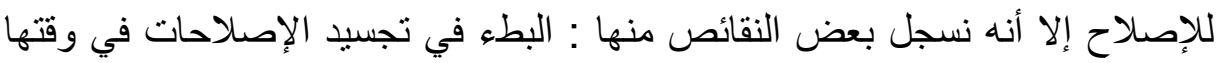

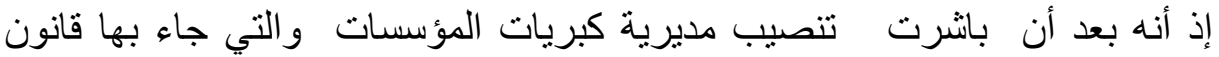

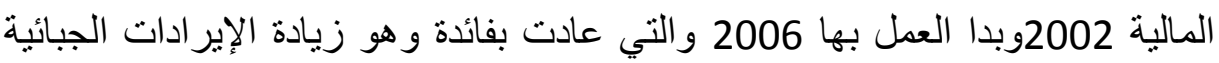

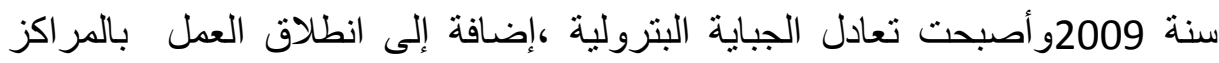

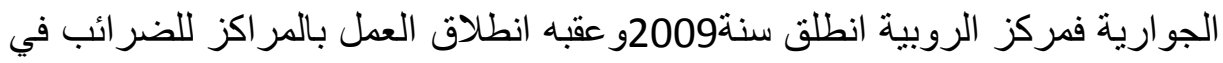

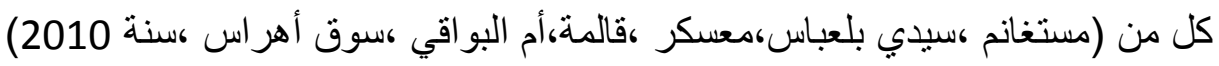

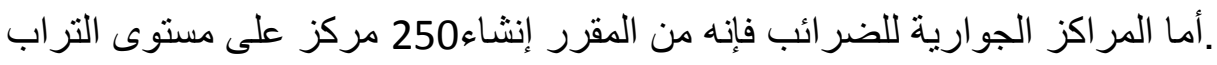

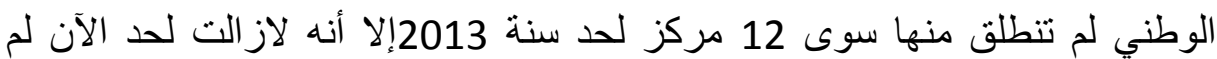

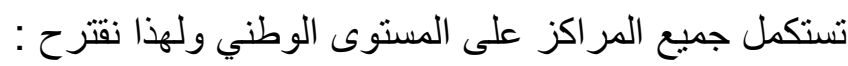

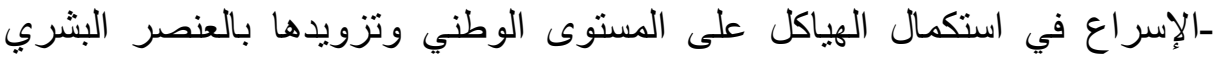

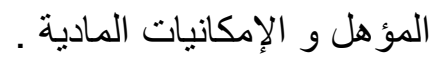

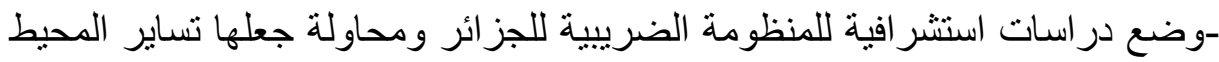

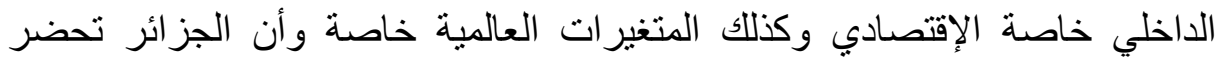
للانضمام للمنظمة العالمية للتجارة . لاصمي وكية 
قائمة الهوامش و المراجع

(1) يونس أحمد البطريق، مقدمة في النظم الضريبية، المكتب المصري الحديث

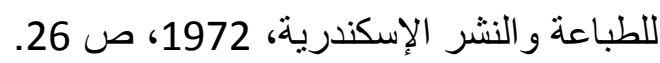

(2)منسي أسعد عبد المالك، اقتصاديات المالية العامة، مطبعة مخيم، 1970، صلإئ، ص

(3)PIERRE BELTRAME " fiscalité en France " édition Hachette, Livre Paris, P12.

(4) عبد الكريم صادق بركات "النظم الضريبية" الدار الجامعية، بيروت 1976، ص

(5) رفعت محجوب " المالية العامة" دار النهضة العربية، بيروت 1979، ص ص 204. (6) اوشأن احمد/أد للعزة و بن علي ، الأكاديمية للار اسات الاجتماعية والإنسانية/قسم

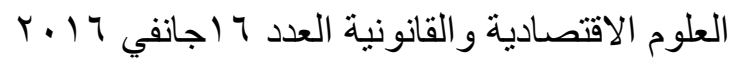

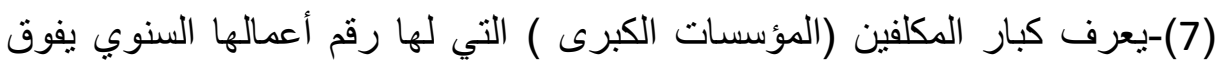
100مليون دج المؤسسات البترولية ،المؤسسات الأجنبية ،

Lettre de la dgi 21 juillet 2005

(8)- محد قدوش ،اليوم الإعلامي للإصلاحات الجبائية ،مشروع مر اكز الضرائب

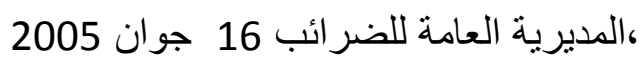

(9)-المادة 3مكرر من المرسوم التنفيذي المتضمن إنشاء مديرية كبريات المؤسسات

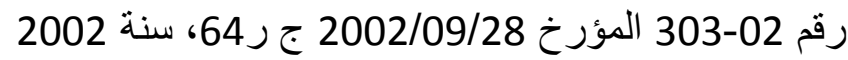
(10)-المادة 160 من قانون الإجر اءعات الجبائية

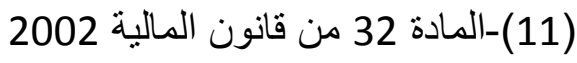

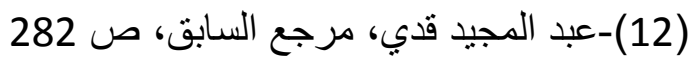

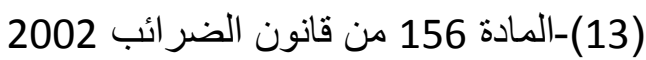

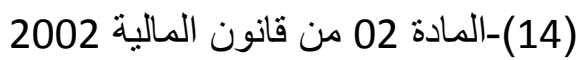

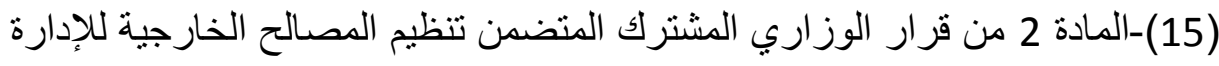
الجبائية فيفري)

(16)-المادة 3 من نفس المرجع السابق

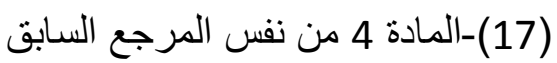

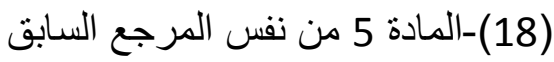

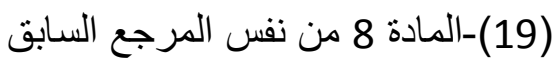
(20)-المادة 9 من نفس المرجع السابق نفيق (21)-المادة 14من نقس المرجع السابق فيق

(22)-lettre de dgi lettre d'information .MF dgi n 122003 p 05 (23)-lettre de la dgi numéro spécial (modernisation de l'administration fiscale et prochaine étape )

$$
\text { 2018/10/1) الموقع الرسمي لمديرية الضر ائب،تاريخ التصفح (24) }
$$


(25)- حميد بوزيدة ،النظام الضريبي الجزائري وتحديات الإصلاح الإقتصادي

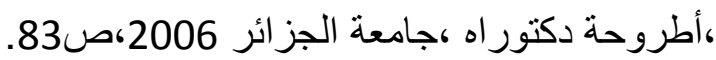

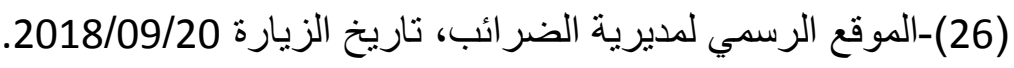

